Article

\title{
Theoretical Study of Nanoporous Graphene Membranes for Natural Gas Purification
}

\author{
Giovanni Tronci, Federico Raffone * and Giancarlo Cicero \\ Dipartimento di Scienza Applicata e Tecnologia, Politecnico di Torino, Corso Duca degli Abruzzi 24, \\ 10129 Torino, Italy; giovanni.tronci@polito.it (G.T.); giancarlo.cicero@polito.it (G.C.) \\ * Correspondence: federico.raffone@polito.it; Tel.: +39-0110904333
}

Received: 31 July 2018; Accepted: 31 August 2018; Published: 3 September 2018

\begin{abstract}
Gas filtration by means of membranes is becoming increasingly important for industrial processes due to its low cost. In particular, membranes can be applied to separate methane in natural gas from pollutants such as hydrogen sulfide and carbon dioxide. The recent advent of nanoporous graphene as material for membranes helped to overcome the current problems of polymeric membranes, namely the permeability/selectivity tradeoff. However, the factors that determine gas filtration through nanoporous graphene are not completely clear yet. In this work, we show that pore size, shape and functionalization severely affect the selectivity of the membrane toward $\mathrm{CO}_{2}$ and $\mathrm{H}_{2} \mathrm{~S}$ with respect to $\mathrm{CH}_{4}$. We identified that the critical diameter of circular pore for the separation of contaminants from methane with graphene membranes is $5.90 \AA$. An elliptical pore is discovered to select gas species having similar sizes on the basis of their shape. The more elongated $\mathrm{CO}_{2}$ is allowed to pass though the pore while the more spherical $\mathrm{H}_{2} \mathrm{~S}$ and $\mathrm{CH}_{4}$ are rejected. Finally, the gas-membrane interactions are found to decisively affect the filtration performances. Functionalization with hydroxyl groups led to a higher permeability of the gas species with polar bonds while keeping an excellent selectivity.
\end{abstract}

Keywords: gas purification; molecular dynamics; membrane; graphene

\section{Introduction}

Natural gas is regarded as one of the most important fossil fuels for energy production in the modern economy. Unlike other fossil fuels, natural gas combustion in stoichiometric conditions does not produce any dangerous pollutant, like $\mathrm{SO}_{2}$ and $\mathrm{NO}_{x}$, but rather it gives rise to gas containing mainly $\mathrm{CO}_{2}$ and $\mathrm{H}_{2} \mathrm{O}$ [1]. Furthermore, compared to other fossil fuels, natural gas produces a smaller amount of $\mathrm{CO}_{2}$ molecules, reducing the risk of greenhouse effect. For these reasons and the lack of reliable renewable resources, natural gas is expected to be as important in the future as it is today [2]. Methane is the main component of the natural gas, although other contaminants, such as hydrogen sulfide and carbon dioxide, are present in its composition. A purification process must then be performed to remove these impurities before its use. Typically, the process consists in the absorption-desorption, also referred to as gas sweetening, of the impurities in aqueous amine solutions that allows for achieving the required gas purity [3]. However, the gas sweetening process has some technological disadvantages like the loss of amine solutions, the steam inclusion in the natural gas phase during the desorption step and the degradation of amine in corrosive byproducts [4]. The main concern is the elevated cost of the process as a consequence of the amine solution regeneration [4]. To overcome the inherent issues of the gas sweetening process, another approach has been proposed: gas filtration by nanoporous membranes [5]. Membrane gas separation relies on the ability of the membrane to allow the passage of specific molecules while rejecting others. Unlike the absorption process, the membrane mediated gas separation could in principle combine both low energy cost and low environmental impact [6]. The first 
membrane technology for gas separation was based on polymeric membranes, which performed poorly in terms of the permeability/selectivity tradeoff [5,7]. Additionally, polymer membranes suffer from plasticization induced by the $\mathrm{CO}_{2}$ gas that results in a strong loss in selectivity [8]. Polymeric membranes can also be coupled with ionic liquids which contribute to the adsorption of natural gas residuals such as $\mathrm{CO}_{2}$. Nevertheless, their industrial application is prevented by the leak out of the ionic liquid through the largest pores of the supporting membrane or due to membrane compression during the filtration [9-12]. Because of these drawbacks, polymeric membranes do not represent a reliable alternative to the absorption-desorption process. However, recently nanoporous graphene was suggested as a new promising material for gas filtration membranes thanks to its unique properties [13-16]. Given that permeability scales inversely with the thickness of the membrane, the one-atom thick graphene is the perfect material to create highly permeable membranes [17]. Furthermore, the possibility to precisely control the pore dimensions [18] provides to nanoporous graphene a very high selectivity to numerous compounds. Another interesting property is its strength and chemical stability that make nanoporous graphene a very durable material [13], able to resist high pressures like the ones applied in the membrane gas separation processes [19]. The excellent performances of graphene as a gas filter are well documented in literature [20]. For instance, C. Sun et al. showed by means of classical molecular dynamics simulations that $\mathrm{H}$ and $\mathrm{N}$ functionalized circular pores in graphene allow the passage of small gas molecules like $\mathrm{N}_{2}, \mathrm{CO}_{2}$ and $\mathrm{H}_{2} \mathrm{~S}$ while blocking methane [15], demonstrating that graphene membranes are effective filters for gas purification. $\mathrm{Ab}$ initio molecular dynamics also confirmed the possibility to separate gas mixtures like $\mathrm{H}_{2} / \mathrm{CH}_{4}$ with similar $\mathrm{H}$ and $\mathrm{N}$-passivated pores predicting a very high selectivity [17]. $\mathrm{H}$. Du et al. tested several different pore sizes and shapes to separate $\mathrm{H}_{2} / \mathrm{N}_{2}$ mixtures. The smallest pores are reported to allow the $\mathrm{H}_{2}$ permeation because of steric effects. Conversely, for bigger pores, $\mathrm{N}_{2}$ is reported to cross the membrane more frequently. The authors explained the observed trend highlighting that Van der Waals interactions between the gas and the membrane are stronger in the case of nitrogen atoms [21]. Experimentally, the gas separation of $\mathrm{H}_{2}, \mathrm{CO}_{2}, \mathrm{Ar}, \mathrm{N}_{2}$ and $\mathrm{CH}_{4}$ mixtures with graphene was assessed with pores generated by ultraviolet etching. After the pore generation only $\mathrm{H}_{2}$ and $\mathrm{CO}_{2}$ are reported to cross the membrane [22]. Mixture of $\mathrm{H}_{2} \mathrm{~S}$ and $\mathrm{CH}_{4}$ were instead reported to be separated by means of carbon-based membranes, specifically carbon nanotubes. An inner diameter of $23 \mathrm{~nm}$ was necessary for the task [23]. Different aspects influencing gas permeation through porous graphene are suggested in literature, however the parameters that mainly affect selectivity and permeability in gas-gas separation are not clear yet. Steric hindrance is known to be important but it is not expected to be the only effect influencing filtration. For instance, different chemistries at the pore edges are likely to play an important role as it is known from first principles simulations that gas molecules adsorb with different strength on $\mathrm{B}, \mathrm{N}, \mathrm{Al}$, and $\mathrm{S}$ doped graphene [24]. As proof of principle, a theoretical study showed that hydrophilic pore passivation with fluorine atoms improves water permeability at low pressures during desalination through nanoporous graphene membranes [25]. In this work we focused on understanding the features that the graphene pores must possess to accomplish $\mathrm{CO}_{2} / \mathrm{CH}_{4}$ and $\mathrm{H}_{2} / \mathrm{CH}_{4}$ separation during natural gas purification to enhance graphene membrane performances. By means of molecular dynamics simulations we demonstrate how pore shape, dimension and chemical functionalization determine the graphene membrane permeance and selectivity.

\section{Method}

Our work was carried out using classical molecular dynamics simulations, which were proven to be able to efficiently model the separation of gas mixtures by means of a graphene membrane [26]. All computations were performed using the Large-scale Atomic/Molecular Massively Parallel Simulator (LAMMPS) software [27]. The "in silico" experimental setup employed to address gas filtration efficiency of porous graphene membranes is reported in Figure 1 and it follows a well-established computational approach [26]. The nanoporous graphene membrane is located in the middle of the supercell. The left side, referred to as feed, contains 400 molecules, divided equimolarly 
between two gas species among $\mathrm{CO}_{2}, \mathrm{H}_{2} \mathrm{~S}$ and $\mathrm{CH}_{4}$, while the right part, the permeate, is left empty at the beginning of the simulation. In the feed, a graphene piston is also placed to generate the pressure that pumps the gas during the experiments. During the simulation, the piston compresses the gas at a pressure of 100 bar, pushing the gas molecules toward the membrane. A theoretical study reported that nanoporous graphene can withstand pressures larger than 500 bar [19]. Graphene membranes are therefore expected not to break during the gas purification process which usually involves much lower pressures. The simulation box dimensions are $42 \times 42 \times 340 \AA$, with periodic boundaries conditions along the $x$ and $y$ directions and reflecting walls along the $z$ direction.

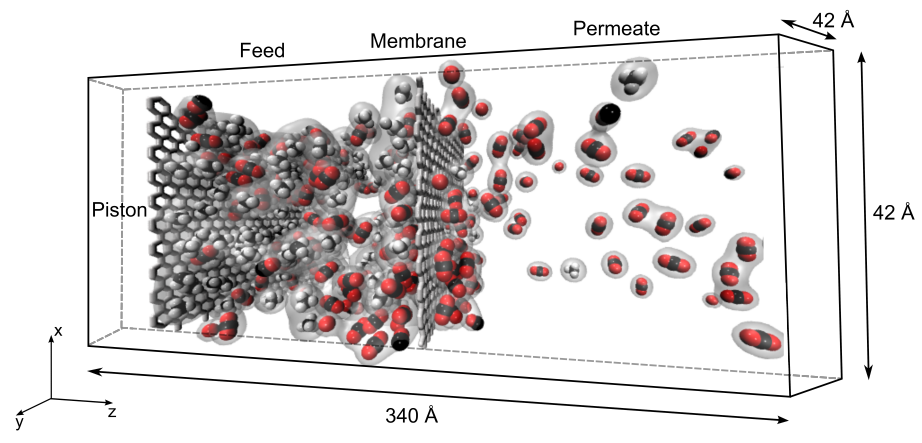

Figure 1. Example of a structure modeling the gas separation process. The graphene membrane is placed in the middle of the cell while the graphene piston is on the left. Carbon atoms are represented in gray/black, oxygens in red and hydrogens in white. The shaded areas represent the Van der Waals surfaces of gas molecules.

The temperature is maintained constant at the value of $300 \mathrm{~K}$ using a Nosé-Hoover thermostat. The simulations are carried out for $51 \mathrm{~ns}$ with a timestep of $0.3 \mathrm{fs}$. Before the separation phase starts, an equilibration step is conducted applying a small piston pressure. After about 0.1 ns the system can be considered to be at the equilibrium and the separation process starts increasing the pressure generated by the piston to 100 bar. During the simulation we counted the number of molecules that passed through the pore of the graphene membrane, in order to calculate membrane permeance and selectivity. The permeance is defined as the amount of molecules that crosses the membrane per unit of pressure, time and area of the membrane, and it is expressed in Gas Permeation Units (GPU; $1 \mathrm{GPU}=3.35 \times 10^{-10} \mathrm{~mol} \mathrm{~s}^{-1} \mathrm{~m}^{-2} \mathrm{~Pa}^{-1}$ ). The selectivity is the ratio between the permeances of the two gases from which the feed is composed. The pair interactions between carbon and hydrogen atoms in graphene and methane are modeled by the AIREBO potential [28]. For the $\mathrm{H}_{2} \mathrm{~S}$ and $\mathrm{CO}_{2}$ molecules we used a combination of Lennard-Jones and Coulombic potential for the interatomic interaction whereas a harmonic potential for the bonded interactions [4]. We employed the Lorentz-Berthelot mixing rule to evaluate the cross parameters. We studied four types of nanoporous membranes having different pores referred to as pore P1, P2, P3 and P3OH as shown in Figure 2.

$\mathrm{P} 1$ is a nearly circular pore obtained by removing 13 carbon atoms from the graphene lattice and passivating the unsaturated carbons with hydrogen atoms. P2 is obtained removing 14 carbon atoms from the graphene lattice forming a more elongated shape with respect to P1. As before, carbon dangling bonds are passivated with hydrogen atoms. P3 is the largest pore, obtained removing 16 carbon atoms and it is functionalized with hydrogens as for the other pores. The last pore, $\mathrm{P} 3 \mathrm{OH}$, corresponds to the pore P3 but with a different functionalization at the pore edges constituted by alternating hydroxyl groups and hydrogens. We highlight that experimentally it is possible to alter the shape, size and functionalization of the graphene pores so as to reproduce the types of pore we are analyzing. For instance, tilting the angle of the electron beam, which is used to locally knock the carbon atoms off the sheet, is said to give rise to more elongated pores [29]. Exposing graphene to 
different reagents allows for the tailoring of the types of functional groups attached at the edge of the pores [30].

a

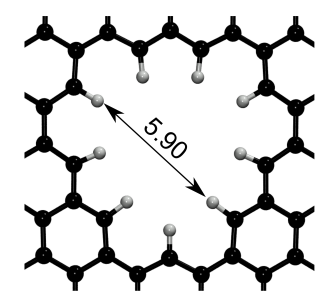

C

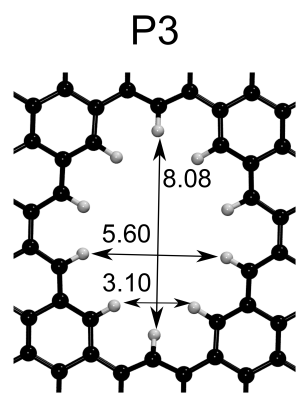

b

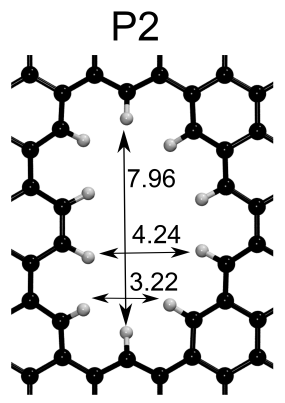

d

d $\mathrm{P} 3 \mathrm{OH}$

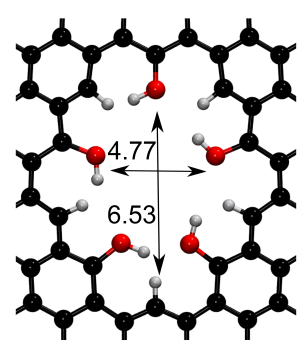

Figure 2. Ball and stick representation of the porous graphene structures employed for gas separation (zoomed on the pore area). Carbon atoms are represented in black, oxygens in red and hydrogens in white. Distances are in Angstrom.

\section{Results and Discussion}

Gas separation by porous graphene membranes is a process that involves the direct interaction between a single gas molecule and the pores. It is then important to understand what differentiates the gas molecules we are aiming at separating so as to determine the factors that influence their tendency to pass through the pore.

A semi-quantitative estimation of the gas molecular size can be obtained considering the Van der Waals radii of the atoms that compose the molecules to be separated. In Figure 3, $\mathrm{CO}_{2}, \mathrm{H}_{2} \mathrm{~S}$ and $\mathrm{CH}_{4}$ are represented schematically. In correspondence of the position of each atom, a sphere representing the Van der Waals surface has been drawn.
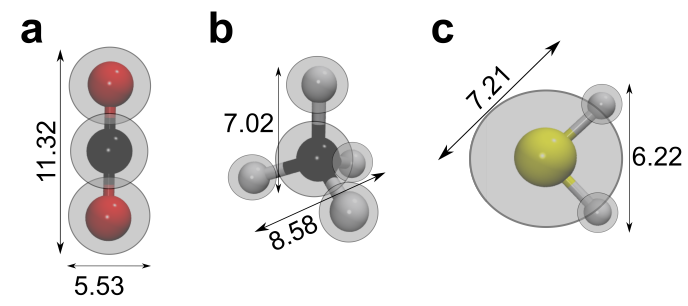

Figure 3. $\mathrm{CO}_{2}(\mathbf{a}), \mathrm{CH}_{4}$ (b) and $\mathrm{H}_{2} \mathrm{~S}$ (c) molecules with their relative sizes in $\AA$. Carbon atoms are shown in black, oxygens in red, hydrogens in white and sulfur in yellow. The dimensions are calculated considering their Van der Waals volumes, whose surfaces are represented as shaded areas.

Methane is the molecule that occupies the largest volume, having a rather spherical steric hindrance with a diameter of $8.5 \AA$. Both carbon dioxide and hydrogen sulfide have at least one 
dimension smaller than the diameter of $\mathrm{CH}_{4}$, making them easier to filter by steric hindrance with respect to methane. Although $\mathrm{CO}_{2}$ and $\mathrm{H}_{2} \mathrm{~S}$ have similar sizes, they differ in shape: $\mathrm{CO}_{2}$ has an elongated shape while $\mathrm{H}_{2} \mathrm{~S}$ is more rounded. We will show that such a difference has particular consequences on their permeance across the pore. Unlike methane, $\mathrm{CO}_{2}$ and $\mathrm{H}_{2} \mathrm{~S}$ are characterized by polar bonds suggesting that polar terminations of the pores, such as hydroxyl groups, might influence the separation performances.

In our work we study the factors that influence the separation process based on the characteristics of the molecules to be filtered and the pore size, shape and edge functionalization. We start analyzing pore P1 which has a circular shape and a diameter of $5.90 \AA$. . At the studied pressures, gas molecules do not aggregate and their interaction occurs only through elastic collisions which appear to be a quite rare event at our simulation scale. As one can see in Table 1 , the pore efficiently separates both the $\mathrm{CO}_{2} / \mathrm{CH}_{4}$ and the $\mathrm{H}_{2} \mathrm{~S} / \mathrm{CH}_{4}$ mixtures. The $\mathrm{CH}_{4}$ permeance in pore $\mathrm{P} 1$ is around $0.01-0.02 \times 10^{5} \mathrm{GPU}$, whereas $\mathrm{CO}_{2}$ and $\mathrm{H}_{2} \mathrm{~S}$ achieve much larger values, $0.25 \times 10^{5} \mathrm{GPU}$ and $0.23 \times 10^{5} \mathrm{GPU}$ respectively, leading to a selectivity of 11 for the $\mathrm{CO}_{2} / \mathrm{CH}_{4}$ mixture and 20 for the $\mathrm{H}_{2} \mathrm{~S} / \mathrm{CH}_{4}$ mixture. For the case of pore $\mathrm{P} 1$, the filtration occurs mostly by steric effect: the methane, as highlighted before, has a larger cross section compared to $\mathrm{CO}_{2}$ and $\mathrm{H}_{2} \mathrm{~S}$, consequently the barrier required to cross the pore is expected to be higher. We verified such a hypothesis performing a Nudged Elastic Band (NEB) simulation of the energy profile of a molecule traveling from the feed to the permeate. The NEB analysis shows that $\mathrm{CH}_{4}$ has to overcome an energy barrier of $0.27 \mathrm{eV}$ to cross the membrane while $\mathrm{CO}_{2}$ and $\mathrm{H}_{2} \mathrm{~S}$ have to overcome a lower barrier, respectively $0.16 \mathrm{eV}$ and $0.17 \mathrm{eV}$. A pore of diameter of $5.90 \AA$ is therefore sufficient to effectively prevent $\mathrm{CH}_{4}$ from passing through the membrane while at the same time it permits the passage of smaller molecules. The results agree with the work by $\mathrm{C}$. Sun et al. who, with the same pore, reported comparable permeances for the $\mathrm{CO}_{2} / \mathrm{CH}_{4}$ and $\mathrm{H}_{2} \mathrm{~S} / \mathrm{CH}_{4}$ mixtures [15].

Table 1. Permeability and selectivity calculated for different gas mixtures and pore types.

\begin{tabular}{|c|c|c|c|}
\hline $\mathrm{CO}_{2} / \mathrm{CH}_{4}$ & $\mathrm{CO}_{2} \mathrm{GPU}\left[\times 10^{5}\right]$ & $\mathrm{CH}_{4} \mathrm{GPU}\left[\times 10^{5}\right]$ & $\mathrm{S}_{\mathrm{CO}_{2} / \mathrm{CH}_{4}}$ \\
\hline P1 & 0.25 & 0.02 & 11 \\
\hline P2 & 0.17 & 0.01 & 15 \\
\hline P3 & 2.39 & 2.4 & 1 \\
\hline $\mathrm{P} 3 \mathrm{OH}$ & 3.25 & 0.55 & 5.9 \\
\hline $\mathrm{H}_{2} \mathrm{~S} / \mathrm{CH}_{4}$ & $\mathrm{H}_{2} \mathrm{~S}$ GPU $\left[\times 10^{5}\right]$ & $\mathrm{CH}_{4} \mathrm{GPU}\left[\times 10^{5}\right]$ & $\mathrm{S}_{\mathrm{H}_{2} \mathrm{~S} / \mathrm{CH}_{4}}$ \\
\hline P1 & 0.23 & 0.01 & 20 \\
\hline P3 & 5.79 & 2.04 & 2.8 \\
\hline $\mathrm{P} 3 \mathrm{OH}$ & 11.91 & 2.07 & 5.7 \\
\hline $\mathrm{CO}_{2} / \mathrm{H}_{2} \mathrm{~S}$ & $\mathrm{CO}_{2} \mathrm{GPU}\left[\times 10^{5}\right]$ & $\mathbf{H}_{2} \mathbf{S}$ GPU $\left[\times 10^{5}\right]$ & $\mathrm{S}_{\mathrm{CO}_{2} / \mathrm{H}_{2} \mathrm{~S}}$ \\
\hline P2 & 0.09 & 0.03 & 2.7 \\
\hline
\end{tabular}

We then tested the performances of pore P2 to understand how pore shape impacts the gas permeance. Compared to P1, P2 has a more stretched contour and it is purposely designed to reproduce the elongated shape of the $\mathrm{CO}_{2}$ molecule. Such a feature has indeed consequences on the selectivity of the $\mathrm{CO}_{2} / \mathrm{CH}_{4}$ mixture: $\mathrm{P} 2$ selectivity to $\mathrm{CO}_{2}$ is indeed higher (15) compared to the one of $\mathrm{P} 1$ (11) as see in Table 1. A lower overall permeance is reported both for $\mathrm{CO}_{2}\left(0.17 \times 10^{5} \mathrm{GPU}\right)$ and $\mathrm{CH}_{4}\left(0.01 \times 10^{5} \mathrm{GPU}\right)$ compared to pore $\mathrm{P} 1$ due to the smaller dimension of $\mathrm{P} 2$ along one pore axis that hinders the passage of both molecules. The energetic barriers calculated via NEB are accordingly higher in $\mathrm{P} 2$ than in $\mathrm{P} 1$ passing from $0.16 \mathrm{eV}$ to $0.28 \mathrm{eV}$ for $\mathrm{CO}_{2}$ and from $0.27 \mathrm{eV}$ to $0.69 \mathrm{eV}$ for $\mathrm{CH}_{4}$. As an additional proof of the shape selectivity of $\mathrm{P} 2$, we filtrated a $\mathrm{CO}_{2} / \mathrm{H}_{2} \mathrm{~S}$ mixture. Despite having similar dimensions, $\mathrm{CO}_{2}$ and $\mathrm{H}_{2} \mathrm{~S}$ differ in shape. This simulation led to a permeance of $0.09 \times 10^{5}$ GPU for $\mathrm{CO}_{2}$ and $0.03 \times 10^{5} \mathrm{GPU}$ for $\mathrm{H}_{2} \mathrm{~S}$ with a $\mathrm{CO}_{2} / \mathrm{H}_{2} \mathrm{~S}$ selectivity of 2.7, proving that the filtration of molecules with comparable size is possible thanks to shape selective pores. In the framework of an 
industrial process, graphene membranes with elliptic pores can be used as second stage separation membranes to severely reduce the concentration of the dangerous $\mathrm{H}_{2} \mathrm{~S}$ gas in the $\mathrm{CO}_{2} / \mathrm{H}_{2} \mathrm{~S}$ mixture remaining after the initial natural gas purification process. For the $\mathrm{H}_{2} \mathrm{~S}$ to cross pore $\mathrm{P} 2$, an energy barrier comparable with $\mathrm{CH}_{4}$ must be overcome $(0.69 \mathrm{eV})$. For this reason, there is not a noticeable difference in gas permeance of the $\mathrm{H}_{2} \mathrm{~S} / \mathrm{CH}_{4}$ mixture within the timespan of our simulation (51 ns).

To test the effects of pore dimensions on the separation process, we run simulations with a larger pore, P3, having an area of $35.15 \AA^{2}$ compared to $27.34 \AA^{2}$ of P1. The increased area of the pore leads to a higher permeance $\left(2.39 \times 10^{5} \mathrm{GPU}\right.$ for $\mathrm{CO}_{2}$ and $5.79 \times 10^{5} \mathrm{GPU}$ for $\mathrm{H}_{2} \mathrm{~S}$, respectively for the $\mathrm{CO}_{2} / \mathrm{CH}_{4}$ and $\mathrm{H}_{2} \mathrm{~S} / \mathrm{CH}_{4}$ mixtures) and less selectivity ( 1 for $\mathrm{CO}_{2} / \mathrm{CH}_{4}$ and $2.8 \mathrm{H}_{2} \mathrm{~S} / \mathrm{CH}_{4}$ ) than the previous pores. Therefore, the critical diameter that a circular pore must have in order to separate methane from $\mathrm{CO}_{2}$ and $\mathrm{H}_{2} \mathrm{~S}$, is around $5.90 \AA$. A similar diameter was also proven to filter salt ions from water during desalination [26]. In comparison, A. Khakpay et al. [31] showed that $\mathrm{CH}_{4}$ permeance is even larger than the one of $\mathrm{CO}_{2}$ through a larger elliptic pore (10-12 $\AA$ ). Such a behavior indicates that, beyond a critical diameter, steric hindrance no longer contributes to selectivity and that for the natural gas purification to take place one must rely on other factors such as pore shape and functionalization. As we can see from the $\mathrm{H}_{2} \mathrm{~S}$ permeance, hydrogen sulfide is slightly favored to pass compared to $\mathrm{CO}_{2}$ and $\mathrm{CH}_{4}$. The higher permeance of $\mathrm{H}_{2} \mathrm{~S}$, however, is not sufficiently supported by considerations on the height of barrier required to cross the pore P3. In fact, both $\mathrm{CH}_{4}$ and $\mathrm{CO}_{2}$ have a very low barrier of $0.08 \mathrm{eV}$ while the filtration of $\mathrm{H}_{2} \mathrm{~S}$ proceeds barrier-less. Even though one of the dimensions of pore $\mathrm{P} 3$ is smaller than the dimensions of pore $\mathrm{P} 1, \mathrm{CH}_{4}$ can easily cross it when slightly tilted since the pore $\mathrm{H}-\mathrm{H}$ diagonal distance is large enough to allow its passage. The higher permeance of $\mathrm{H}_{2} \mathrm{~S}$ can be understood in terms of number of attempts to cross the pore per unit of time. From an analysis of the MD trajectories it can be noticed that $\mathrm{H}_{2} \mathrm{~S}$ concentration is higher closer to the membrane compared to $\mathrm{CO}_{2}$ and $\mathrm{CH}_{4}$. Hydrogen sufide has, indeed, stronger Van der Waals interactions with the graphene membrane compared to the other two molecules, meaning that it is more likely to stick on the membrane surface and diffuse toward the pore. Since there is no crossing barrier, $\mathrm{H}_{2} \mathrm{~S}$ drops down in the pore easily even if it has lost most of its translational velocity toward the membrane. A similar phenomenon is also reported for the filtration of $\mathrm{N}_{2} / \mathrm{H}_{2}$ mixtures by means of graphene membranes where the larger interactions of $\mathrm{N}_{2}$ with the membrane surface favor its permeation [21]. We stress that in our calculations the feed initially contains an equal amount of $\mathrm{CH}_{4}$ and $\mathrm{H}_{2} \mathrm{~S}$. As a result, the number of pore crossing attempts of $\mathrm{H}_{2} \mathrm{~S}$ is overestimated. We expect the $\mathrm{CH}_{4}$ permeance to be higher in real separation processes because of its larger concentration occurring in natural gas.

With pore $\mathrm{P} 3$ we proved that gas-membrane interactions play a role in the separation performance. We then designed a pore, $\mathrm{P} 3 \mathrm{OH}$, which could enhance these interactions at the edges of the pore. The pore $\mathrm{P} 3 \mathrm{OH}$ is obtained by substituting half of the hydrogens saturating the carbon atoms of the pore with hydroxyl groups. Hydroxyl groups were chosen for their affinity with $\mathrm{CO}_{2}$ and $\mathrm{H}_{2} \mathrm{~S}$, given that all of them are characterized by more polar bonds compared to $\mathrm{CH}_{4}$. The pore $\mathrm{P} 3 \mathrm{OH}$ confirmed the importance of gas-pore interactions, showing not only a permeance increase $\left(3.25 \times 10^{5}\right.$ of $\mathrm{P3OH}$ with respect to $2.39 \times 10^{5}$ of $\mathrm{P} 3$ for $\mathrm{CO}_{2} / \mathrm{CH}_{4}$ case, and $11.91 \times 10^{5}$ of $\mathrm{P} 3 \mathrm{OH}$ with respect to $5.79 \times 10^{5}$ of P3 for $\mathrm{H}_{2} \mathrm{~S} / \mathrm{CH}_{4}$ case), but also an improvement of the selectivity (5.9 of $\mathrm{P} 3 \mathrm{OH}$ with respect to 1 of $\mathrm{P} 3$ for $\mathrm{CO}_{2} / \mathrm{CH}_{4}$ case, and 5.7 of $\mathrm{P} 3 \mathrm{OH}$ with respect to 2.8 of $\mathrm{P} 3$ for $\mathrm{H}_{2} \mathrm{~S} / \mathrm{CH}_{4}$ case). We had tested also pore $\mathrm{P} 2 \mathrm{OH}$ and, since $\mathrm{OH}$ functionalization decreases the overall area of the pores, we found that no gas molecule can pass through $\mathrm{P} 2 \mathrm{OH}$. A detailed analysis of the MD trajectories during gas separation simulations of pore $\mathrm{P} 3 \mathrm{OH}$ shows that the electrostatic interaction between hydroxyl groups and $\mathrm{CO}_{2}$ or $\mathrm{H}_{2} \mathrm{~S}$, ensures that the molecules take the most favorable orientation to cross the pores. This finding is in accordance with the literature suggestion that a charged graphene membrane is able to enhance $\mathrm{CO}_{2}$ fluxes through the pores. $\mathrm{CO}_{2}$ molecules, unlike $\mathrm{CH}_{4}$, are indeed reported to stick more easily to the graphene membrane and to access the pores [32]. Pore $\mathrm{P} 3 \mathrm{OH}$ showed that the functionalization is also a key factor to have good separation performance in membrane technology. On the basis of 
our results we can distinguish between two regimes. When the pore size is large, the main role is played by the membrane-gas interaction as the molecules characterized by the largest Van der Waals interactions are more likely to stick at the membrane surface, diffuse along the surface and then drop into the pore without needing much energy as the transition is almost barrier-less. When the pore size is small enough to give rise to a relevant barrier for its crossing, it is rather the gas-pore termination interaction and the temperature that become important as molecules need to approach the pore with the correct orientation and they need a sufficient amount of kinetic energy to overcome the barrier.

\section{Conclusions}

In conclusion, in our study we have shown how the size, the shape and the functionalization of pores in graphene membranes decisively affect the permeance of $\mathrm{CO}_{2}, \mathrm{H}_{2} \mathrm{~S}$ and $\mathrm{CH}_{4}$ molecules. We found that circular pores of $5.90 \AA$ diameter can reject by steric hindrance $\mathrm{CH}_{4}$ while ensuring the permeation of $\mathrm{CO}_{2}$ and $\mathrm{H}_{2} \mathrm{~S}$. A membrane containing such pores can be effectively employed in the natural gas purification process. A pore can be selective also on the basis of the shape of the gas molecules. We proved that a pore matching the elongated size of $\mathrm{CO}_{2}$ can filter out $\mathrm{H}_{2} \mathrm{~S}$. Consequently, a second membrane can be used to separate $\mathrm{CO}_{2}$ from $\mathrm{H}_{2} \mathrm{~S}$, once all the $\mathrm{CH}_{4}$ molecules have been removed. Finally, gas-pore interactions play a significant role. In particular, the hydroxyl functionalization may enhance the permeance of the membrane without sacrificing its selectivity as polar interactions drove both $\mathrm{CO}_{2}$ and $\mathrm{H}_{2} \mathrm{~S}$ toward the pore. In general, one must take into account all the highlighted factors in the design of a membrane process suitable for the species that one aims at separating. Based on the results of our simulations, we suggest that a natural gas separation process should initially consist of membranes with a relatively large pore size, such as pore P3. These would block all the large contaminants such as relatively long chain alkane, while allowing the passage of small molecules such as $\mathrm{CH}_{4}, \mathrm{CO}_{2}$ and $\mathrm{H}_{2} \mathrm{~S}$. Afterwards, the permeated gas would have to go through a second separation process with membranes containing $\mathrm{P} 3 \mathrm{OH}$ pores, which would retain all methane molecules, generating as permeate a mixture of $\mathrm{CO}_{2}$ and $\mathrm{H}_{2} \mathrm{~S}$. The latter could then be further pushed through membranes having P2-like pores to effectively separate $\mathrm{CO}_{2}$ from $\mathrm{H}_{2} \mathrm{~S}$. In summary, an appropriate multi-step separation process with nanoporos graphene membranes with different porosity has to be engineered to achieve high methane purity starting from natural gas.

Author Contributions: Conceptualization, F.R. and G.C.; Methodology, F.R. and G.C.; Investigation, G.T.; Writing-Original Draft Preparation, G.T..; Writing-Review \& Editing, F.R. and G.C.; Funding Acquisition, G.C.

Funding: This work is part of the "DESAL" project funded by Politecnico di Torino.

Acknowledgments: We acknowledge the CINECA award under the ISCRA initiative and HPC@POLITO for the availability of high- performance computing resources and support.

Conflicts of Interest: The authors declare no conflicts of interest.

\section{Abbreviations}

The following abbreviations are used in this manuscript:

GPU Gas Permeation Units

NEB Nudged Elastic Band

\section{References}

1. Energy Information Administration. Natural Gas 1998: Issues and Trends; Energy Information Administration: Washington, DC, USA, 1998.

2. Energy Information Administration. International Energy Outlook; Energy Information Administration: Washington, DC, USA, 2008.

3. Hussain, M.; Abbas, N.; Fino, D.; Russo, N. Novel mesoporous silica supported ZnO adsorbents for the desulphurization of biogas at low temperatures. Chem. Eng. J. 2011, 29, 222-232. [CrossRef] 
4. Karadas, F.; Atilhan, M.; Aparicio, S. Review on the Use of Ionic Liquids (ILs) as Alternative Fluids for $\mathrm{CO}_{2}$ Capture and Natural Gas Sweetening. Energy Fuels 2010, 24, 5817-5828. [CrossRef]

5. Robeson, L.M. Polymer membranes for gas separation. Curr. Opin. Solid State Mater. Sci. 1999, 4, 549-552. [CrossRef]

6. Sanders, D.F.; Smith, Z.P.; Guo, R.; Robeson, L.M.; McGrath, J.E.; Paul, D.R.; Freeman, B.D. Energy-efficient polymeric gas separation membranes for a sustainable future: A review. Polymer 2013, 54, 4729-4761. [CrossRef]

7. Robeson, L.M. The upper bound revisited. J. Membr. Sci. 2008, 320, 390-400. [CrossRef]

8. Suleman, M.S.; Lau, K.K.; Yeong, Y.F. Plasticization and Swelling in Polymeric Membranes in $\mathrm{CO}_{2}$ Removal from Natural Gas. Chem. Eng. Technol. 2016, 39, 1604-1616. [CrossRef]

9. Albo, J.; Luis, P.; Irabien, A. Carbon Dioxide Capture from Flue Gases Using a Cross-Flow Membrane Contactor and the Ionic Liquid 1-Ethyl-3-methylimidazolium Ethylsulfate. Ind. Eng. Chem. Res. 2010, 49, 11045-11051. [CrossRef]

10. Albo, J.; Luis, P.; Irabien, A. Absorption of coal combustion flue gases in ionic liquids using different membrane contactors. Desalin. Water Treat. 2011, 27, 54-59. [CrossRef]

11. Tan, M.; Lu, J.; Zhang, Y.; Jiang, H. Ionic Liquid Confined in Mesoporous Polymer Membrane with Improved Stability for $\mathrm{CO} / \mathrm{N}_{2}$ Separation. Nanomaterials 2017, 10, 299. [CrossRef] [PubMed]

12. Zhao, W.; He, G.; Nie, F.; Zhang, L.; Feng, H.; Liu, H. Membrane liquid loss mechanism of supported ionic liquid membrane for gas separation. J. Membr. Sci. 2012, 411, 73-80. [CrossRef]

13. Lee, C.; Wei, X.; Kysar, J.W.; Hone, J. Measurement of the Elastic Properties and Intrinsic Strength of Monolayer Graphene. Science 2008, 321, 385-388. [CrossRef] [PubMed]

14. Sun, C.; Wen, B.; Bai, B. Recent advances in nanoporous graphene membrane for gas separation and water purification. Sci. Bull. 2015, 60, 1807-1823. [CrossRef]

15. Sun, C.; Wen, B.; Bai, B. Application of Nanoporous Graphene Membranes in Natural Gas Processing: Molecular Simulations of $\mathrm{CH}_{4} / \mathrm{CO}_{2}, \mathrm{CH}_{4} / \mathrm{H}_{2} \mathrm{~S}$ and $\mathrm{CH}_{4} / \mathrm{N}_{2}$. Chem. Eng. Sci. 2015, 138, 616-621. [CrossRef]

16. Booth, T.J.; Blake, P.; Nair, R.R.; Jiang, D.; Hill, E.W.; Bangert, U.; Bleloch, A.; Gass, M.; Novoselov, K.S.; Katsnelson, M.I.; et al. Macroscopic Graphene Membranes and Their Extraordinary Stiffness. Nano Lett. 2008, 8, 2442-2446. [CrossRef] [PubMed]

17. Jiang, D.E.; Cooper, V.R.; Dai, S. Porous Graphene as the Ultimate Membrane for Gas Separation. Nano Lett. 2009, 9, 4019-4024. [CrossRef] [PubMed]

18. Fischbein, M.D.; Drnidc, M. Electron beam nanosculpting of suspended graphene sheets. Appl. Phys. Lett. 2008, 93, 113107. [CrossRef]

19. Cohen-Tanugi, D.; Grossman, J.C. Mechanical Strength of Nanoporous Graphene as a Desalination Membrane. Nano Lett. 2014, 14, 6171-6178. [CrossRef] [PubMed]

20. Celebi, K.; Buchheim, J.; Wyss, R.M.; Droudian, A.; Gasser, P.; Shorubalko, I.; Kye, J.I.; Lee, C.; Park, H.G. Ultimate Permeation Across Atomically Thin Porous Graphene. Science 2014, 344, 289-292. [CrossRef] [PubMed]

21. Du, H.; Li, J.; Zhang, J.; Su, G.; Li, X.; Zhao, Y. Separation of Hydrogen and Nitrogen Gases with Porous Graphene Membrane. J. Phys. Chem. C 2011, 115, 23261-23266. [CrossRef]

22. Koenig, S.P.; Wang, L.; Pellegrino, J.; Bunch, J.S. Selective Molecular Sieving through Porous Graphene. Nat. Nanotechnol. 2012, 7, 728. [CrossRef] [PubMed]

23. Gilania, N.; Towfighi, J.; Rashidi, A.; Mohammadi, T.; Omidkhah, M.R.; Sadeghian, A. Investigation of $\mathrm{H}_{2} \mathrm{~S}$ Separation from $\mathrm{H}_{2} \mathrm{~S} / \mathrm{CH}_{4}$ Mixtures Using Functionalized and Non-Functionalized Vertically Aligned Carbon Nanotube Membranes. Appl. Surf. Sci. 2013, 270, 115-123. [CrossRef]

24. Dai, J.; Yuan, J.; Giannozzi, P. Gas adsorption on graphene doped with B, N, Al, and S: A theoretical study. Appl. Phys. Lett. 2009, 95, 232105. [CrossRef]

25. Jafarzadeh, R.; Azamat, J.; Erfan-Niya, H. Fluorine-functionalized nanoporous graphene as an effective membrane for water desalination. Struct. Chem. 2018, doi:10.1007/s11224-018-1162-9. [CrossRef]

26. Cohen-Tanugi, D.; Grossman, J.C. Water Desalination across Nanoporous Graphene. Nano Lett. 2012, 12, 3602-3608. [CrossRef] [PubMed]

27. Plimpton, S. Fast Parallel Algorithms for Short-Range Molecular Dynamics. J. Comput. Phys. 1995, 117, 1-19. [CrossRef] 
28. Stuart, S.J.; Tutein, A.B.; Harrison, J.A. A reactive potential for hydrocarbons with intermolecular interactions. J. Chem. Phys. 2000, 112, 6472-6486. [CrossRef]

29. Bai, Z.; Zhang, L.; Li, H.; Liu, L. Nanopore Creation in Graphene by Ion Beam Irradiation: Geometry, Quality, and Efficiency. ACS Appl. Mater. Interfaces 2016, 8, 24803-24809. [CrossRef] [PubMed]

30. Mahmoud, K.A.; Mansoor, B.; Mansour, A.; Khraisheh, M. Functional graphene nanosheets: The next generation membranes for water desalination. Desalination 2015, 356, 208-225. [CrossRef]

31. Khakpay, A.; Rahmani, F.; Nouranian, S.; Scovazzo, P. Molecular Insights on the $\mathrm{CH}_{4} / \mathrm{CO}_{2}$ Separation in Nanoporous Graphene and Graphene Oxide Separation Platforms: Adsorbents versus Membranes. J. Phys. Chem. C 2017, 121, 12308. [CrossRef]

32. Sun, C.; Bai, B. Improved $\mathrm{CO}_{2} / \mathrm{CH}_{4}$ Separation Performance in Negatively Charged Nanoporous Graphene Membranes. J. Phys. Chem. C 2018, 122, 6178. [CrossRef]

(C) 2018 by the authors. Licensee MDPI, Basel, Switzerland. This article is an open access article distributed under the terms and conditions of the Creative Commons Attribution (CC BY) license (http://creativecommons.org/licenses/by/4.0/). 